\title{
EMBROIDERED CHOLIES OF PAHARI REGION: A TECHNICAL STUDY
}

\author{
Dr. Rohini Arora ${ }^{1 凶(D)}$ \\ Assistant Professor, Guru Gobind Singh College for Women, Sector 26, Chandigarh, India
}

Received 20 October 2021

Accepted 29 November 2021

Published 07February 2022

\section{CorrespondingAuthor}

Dr. Rohini Arora, drrohini80@gmail.com DOI

\subsection{1/shodhkosh.v3.i1.2022.68}

Funding: This research received no specific grant from any funding agency in the public, commercial, or not-for-profit sectors.

Copyright: (C) 2022 The Author(s). This is an open access article distributed under the terms of the Creative Commons Attribution License, which permits unrestricted use, distribution, and reproduction in any medium, provided the original author and source are credited.

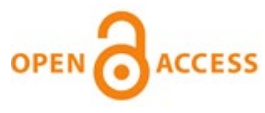

\section{ABSTRACT}

Pahari embroidery was practiced in different parts in undivided Punjab and Himachal Pradesh. The surface ornamentation of these articles with respect to design, raw material and technique were beautifully adapted according to their utility. The popular product in embroidery is Chamba rumals locally known as dhaknu or chabbu. In addition, equally fascinating embroidery was seen on household products which were meant for personal use and decoration in single sided stitches. The most startling are cholies from Himachal Pradesh in terms of their construction and designs. The cholies from given museums were studied namely Bhuri Singh Museum, Chamba, Government Museum and Art Gallery, Chandigarh National Museum, New Delhi, and personal collection. Evidently, they are characterized by selective treatment given to them in terms of construction, materials, stitches, adaptation of designs and motifs. Apart from embroidery miniature paintings also indicated the relevance of traditional costumes in socio cultural traditions. Interestingly two different kinds are observed in cholies according to their construction. Likewise on basis of designs and motifs two different styles in embroidery are seen i.e., free hand curved designs and geometrical designs. The documentation of these designs is done by redrawing the traditional motifs with help of miniature artist Shri Prixit Sharma, Chamba. The stitches are also classified as filling, outline and finishing used in single sided embroidery. Conspicuously these minute variations lend special features to choli blouses and distinguish them from other form of embroideries from the pahari region.

Keywords: Pahari, Choli, Free Hand Curved Designs, Geometrical Designs

\section{INTRODUCTION}

Choli is a women's stitched garment for covering upper part of body. It evidently witnesses wide variations in different regions in India. It is known by different indigenous names such as angia, kasani, tani, phundia, kapadu, polka, kurpasa, kurpasaka. The reference of female upper garment 'kurtaka' is also given by 'अल बिरुनी' which dated back to $10-11$ th century which mentions उनकी कुर्तका (जो स्त्रियो का एक पहनवा है जो कंधे से शरीर के मध्य भाग तक आस्तीनों वाली होती है) के पल्ले मे दाहिनी और बाई दोनों और चीर होते है' . However, these upper garments differ from each other with respect to their construction, designs, and technique. According to Goswamy (1993) , these are widely adopted by the people of North India, especially in Punjab and Rajasthan, and with its great popularity among the Rajput's, the short bodice became a prominent presence in medieval times (pp 186). Interestingly, very distinguished spectacular cholies comes from pahari region which has 
invariably witnessed the ruling of Rajput dynasties and similar significant influences. These cholies stand apart amongst its popular counterparts from other Gujarat and Rajasthan; well applauded for their unique construction, designs, and stitches. Furthermore, to understand the socio-cultural significance of pahari cholies it's important to study the additional garments worn along these cholies.

\subsection{EVIDENCE OF COURTLY COSTUME OF PAHARI REGION}

It's noteworthy that costumes are deeply rooted in folk culture of the region and reflected in their traditions and practices. They are apparently studied in arts and crafts of pahari region which is very well depicted by miniature artists and embroiderers in their finest forms. Two different types of costumes are seen in embroidery and miniature paintings. The traditional costume seen in miniature paintings and embroidery is 'peshwaz' which is full ankle length gown having tight bodice cut just below the breast to which a full front opening skirt is attached along with long tight fitted sleeve. It is made in very fine thin semi-transparent cloth like gauze, net, or muslin. This is worn over short choli of a darker shade visible through the fine fabric of peshwaz. The ensemble is completed with straight patterned paijamas, visible through the transparent skirt and long trailing odhani. Some miniatures show women wearing a fully lined peshwaz (Kumar, R, 1999, pp 246). One such peshwaz is available online with anthropology department of National Museum, New Delhi (Figure (http://www.nationalmuseumindia.gov.in/prodCollections.asp?pid=79\&id=8\&lk= dp8). According to the author, it belonged to Rani Sahiba of Baji; it is a courtly garment of Mughal origin, was widely adopted in the pahari kingdoms and frequently depicted in the pahari miniature paintings .

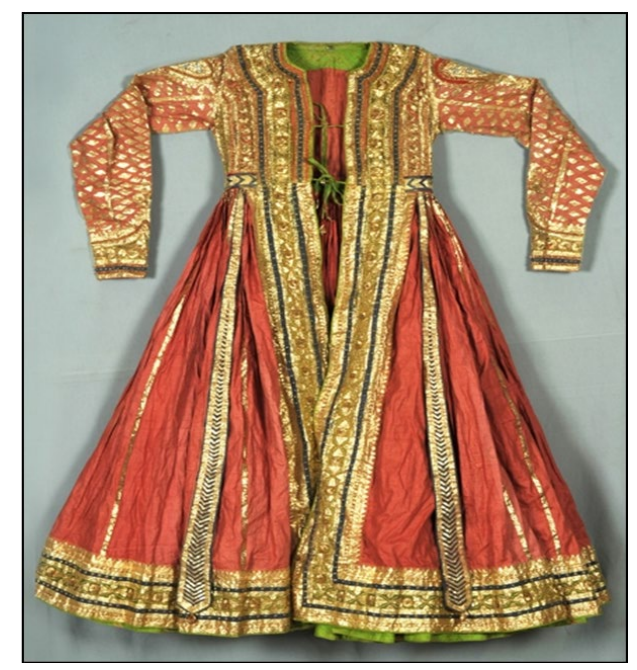

Figure 1 Peshwaj, Courtesy: National Museum.

Source

The similar kind of richly decorated peshwaj is seen in embroidery with zari work and patterns. One of the examples is studied from Catalog of Chamba Rumal, acc no. 64.1, Bhuri Singh Museum, Chamba who depicts the splendor of these costumes in sumptuous way (Figure 2). 


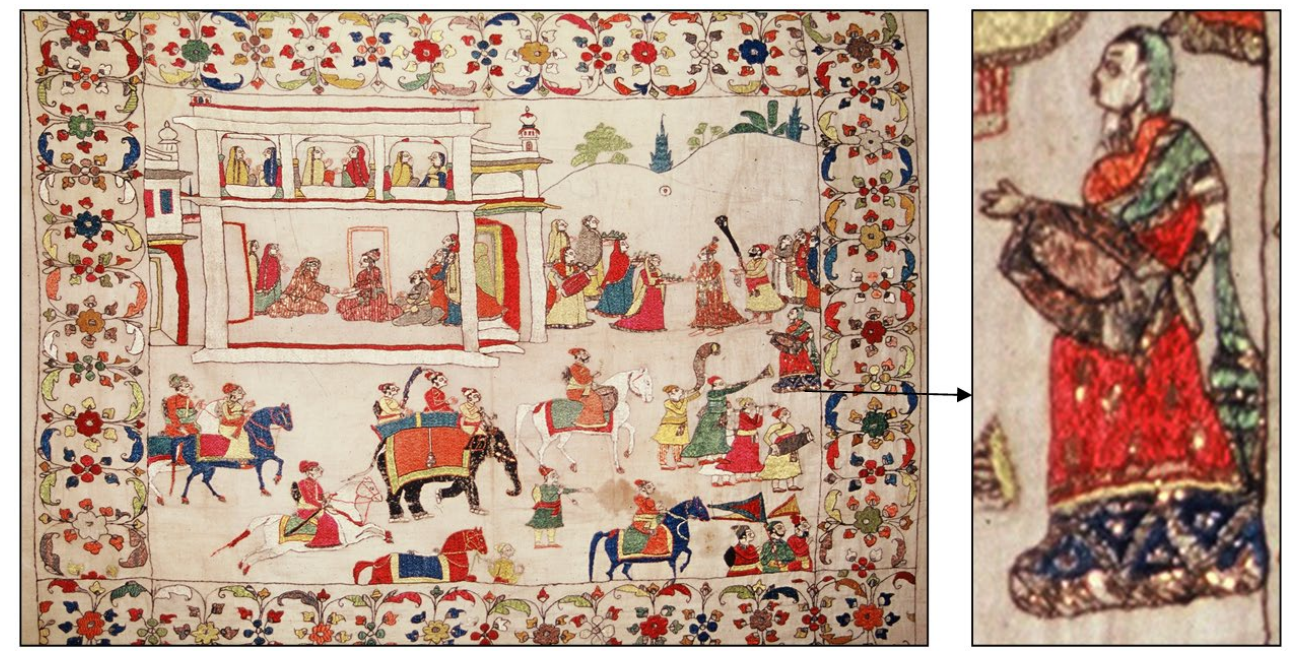

Figure 2 Marriage scene (female shown in richly decorated peshwaj in silk thread and zari; Acc no. 64.1, Courtesy: Bhuri Singh Museum, Chamba.

Apart from these courtly mughal influenced peshwaj another variation is also noticed which seems to be more adorned by common folk of pahari region. Two such rumals from Catalog of Chamba Rumal, acc no. 66.33 .20 and 62.83 Bhuri Singh Museum, Chamba depicting socio cultural traditions; illustrates women wearing sleeveless peshwaj; underneath which different colored full sleeve blouse is worn (Figure 3, Figure 4).

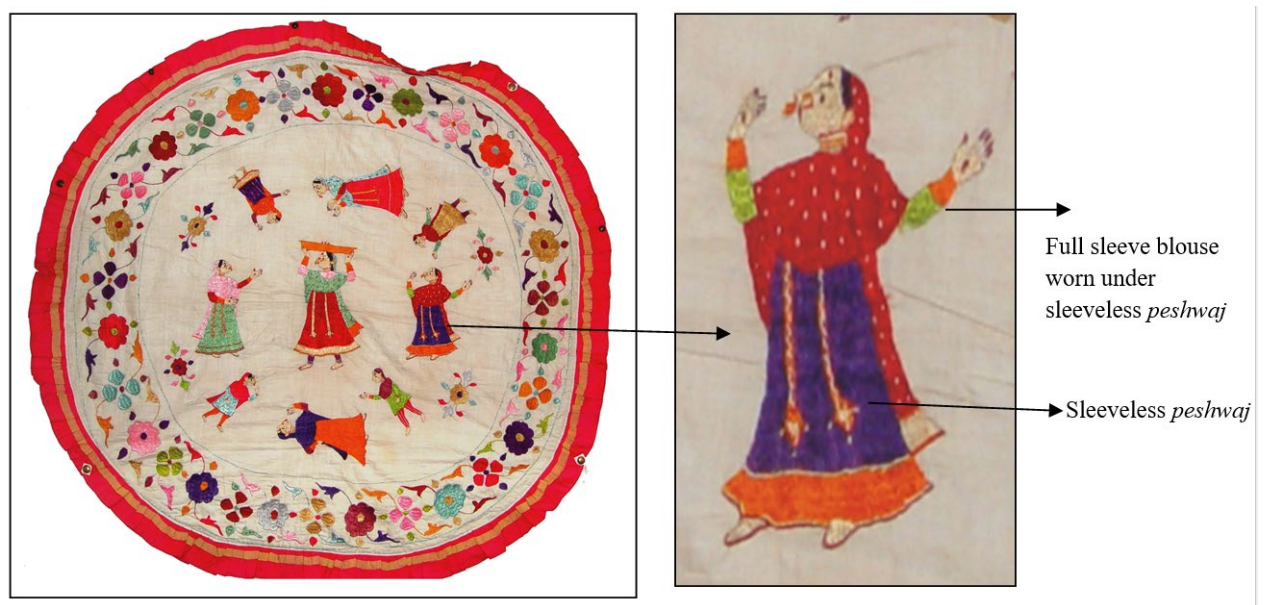

Figure 3 Til chauli (female wearing sleeveless peshwaj with different coloured blouse underneath); Acc no. 66.33.20, Courtesy: Bhuri Singh Museum, Chamba. 


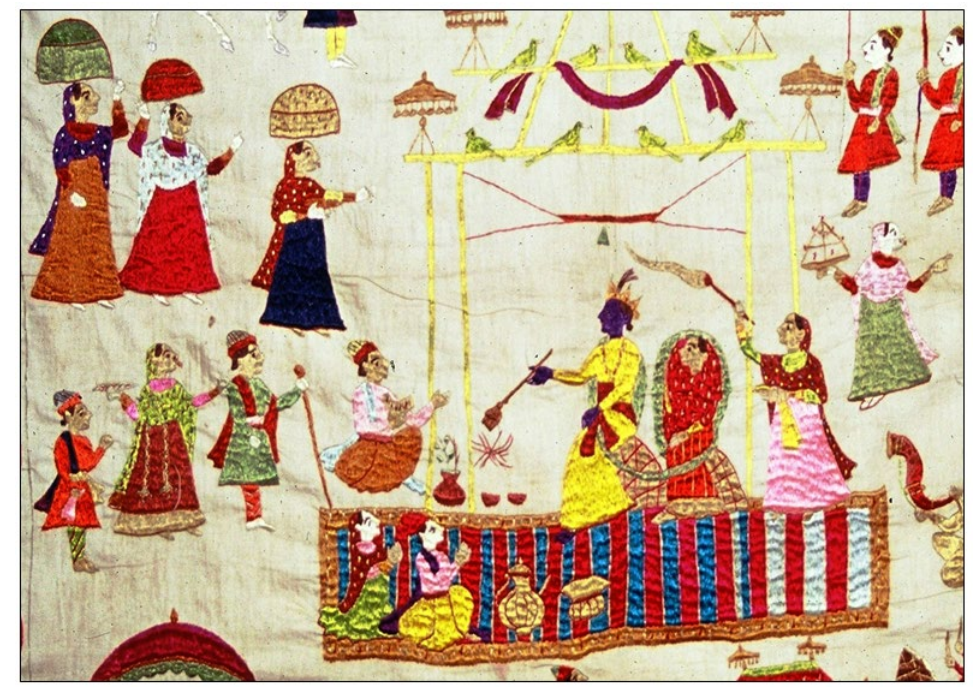

Figure 4 Marriage scene of Krishna and Radha (female attendants shown wearing sleeveless peshwaj with different coloured blouse underneath; Acc no. 62.83, Courtesy: Bhuri Singh Museum, Chamba.

In the field survey, the similar kind of peshwaz is seen, which is sleeveless and worn with full sleeve blouses or woolens underneath them. It is still worn by elder generations on auspicious days or religious ceremonies like tulsi vivah celebrated on last day of kartik month. It is also evident that there are variations seen in the traditional costumes according to communities residing in different places. Even today in Chamba and Bharmour women are wearing similar costumes in cultural events. The most recent is seen in tableau of Himachal Pradesh in Republic Day parade in 2017, where embroiderers are clad in their traditional attires (Figure 5).

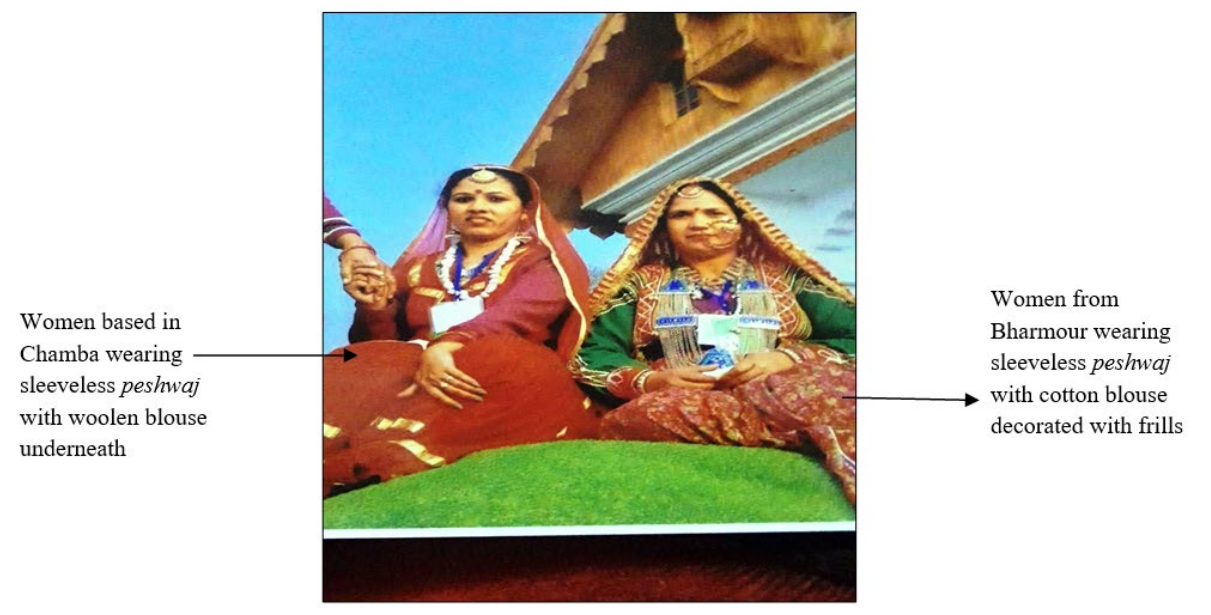

Figure 5 Tableau of Himachal Pradesh showing women in traditional dress, Photo: Author.

\subsection{FOLK COSTUME OF PAHARI REGION}

Other traditional costume popular with common folk seen in embroidery and paintings is small length cholies covering breast area in plain solid colors with ghagra and dupatta. The ghagras are many times elaborately decorated with prints, stripes, or patterns at hem in zari threads. The dupattas are usually plain with zari 
front borders or pallu designs. However, these cholies are very different from actual specimen of pahari cholies housed in various museum collections. According to an author "In the miniature paintings, the choliesworn underneath the gossamer peshwaz seen on the royal ladies and their attendants are of a different kind." As opposed to the rich silk and satin blouses of the royal court, these humble coarse cotton cholies, were hardly seen in the painting. Two such rare paintings are seen in BN Goswamy and Eberhard Fischer 'Pahari Masters: Court Painters of Northern India', pg. 201, pl 81 'Raja Shamsher Sen with Companions in Female Garb' (Figure 6) and 'The Ballad of the Princess and Drummer Boy, pg. 234, pl 96 (Figure 7).

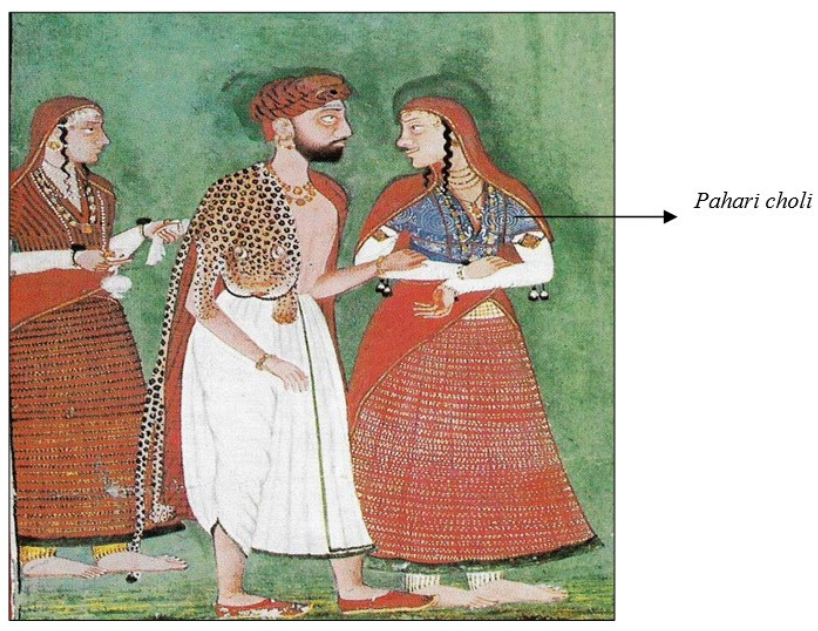

Figure 6 Pahari choli, worn by one of the female attendants; Photo: After Goswamy BN and Fischer E.,2009.

In both the paintings the choli is worn by common folk like in first painting it is worn by male servant and in other by female music player. This clearly indicates its popularity amongst the folk class.

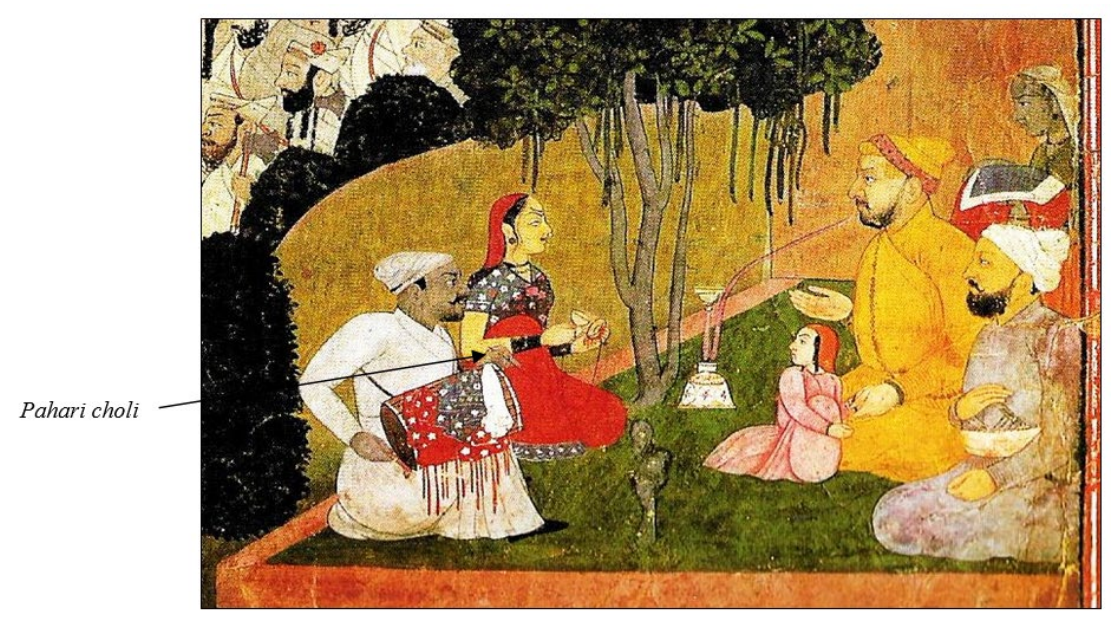

Figure 7 Pahari choli worn by female music player; Photo: After Goswamy BN and Fischer E., 2009. 
The similar attire is housed in collection of Bhuri Singh Museum Gallery, Chamba (Figure 8). It also points that these cholies were worn along with dupattas and wide ghagras with surface prints in khadi printing. According to Museum of Kangra Art, Dharamshala, "These cholies were worn as matter of course by the ladies of Himachal Pradesh along with ghagra and dupatta'. https://somethingtodiscuss.wixsite.com/museumofkanraart/textilegallery?lightbox=dataitem-ixypgcbt).

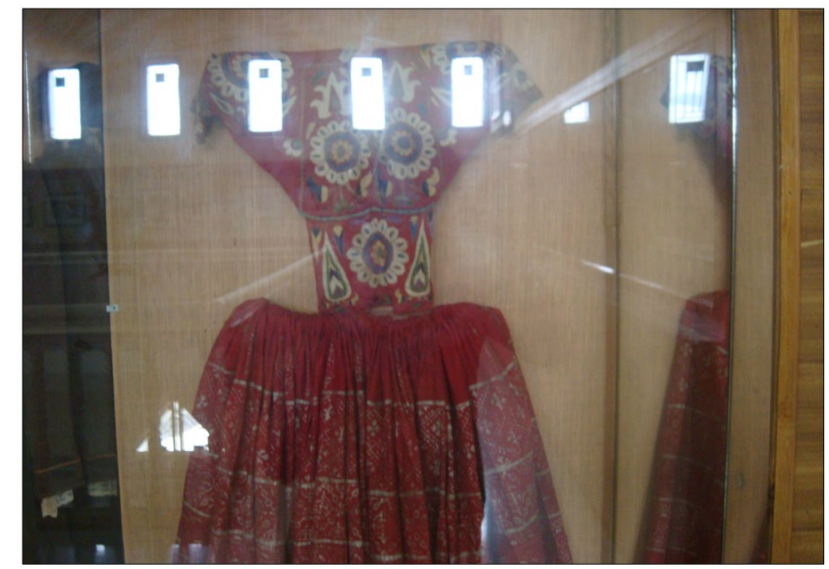

Figure 8 Pahari choli and ghagra housed in Bhuri Singh Museum gallery, Chamba; Photo: Author.

On the other hand, in embroidery cholies without waist flap (petia) along with different colored fabrics in breast area are seen. Silk cholies in mashru cloth are also observed with striped pattern. However, other style in cholies with petia is not noticed. In field survey it was told that pahari cholies are no longer worn but certainly lying with respondents who were interviewed. The cholies given below belong to grand mother of one of the respondents (Figure 9). 

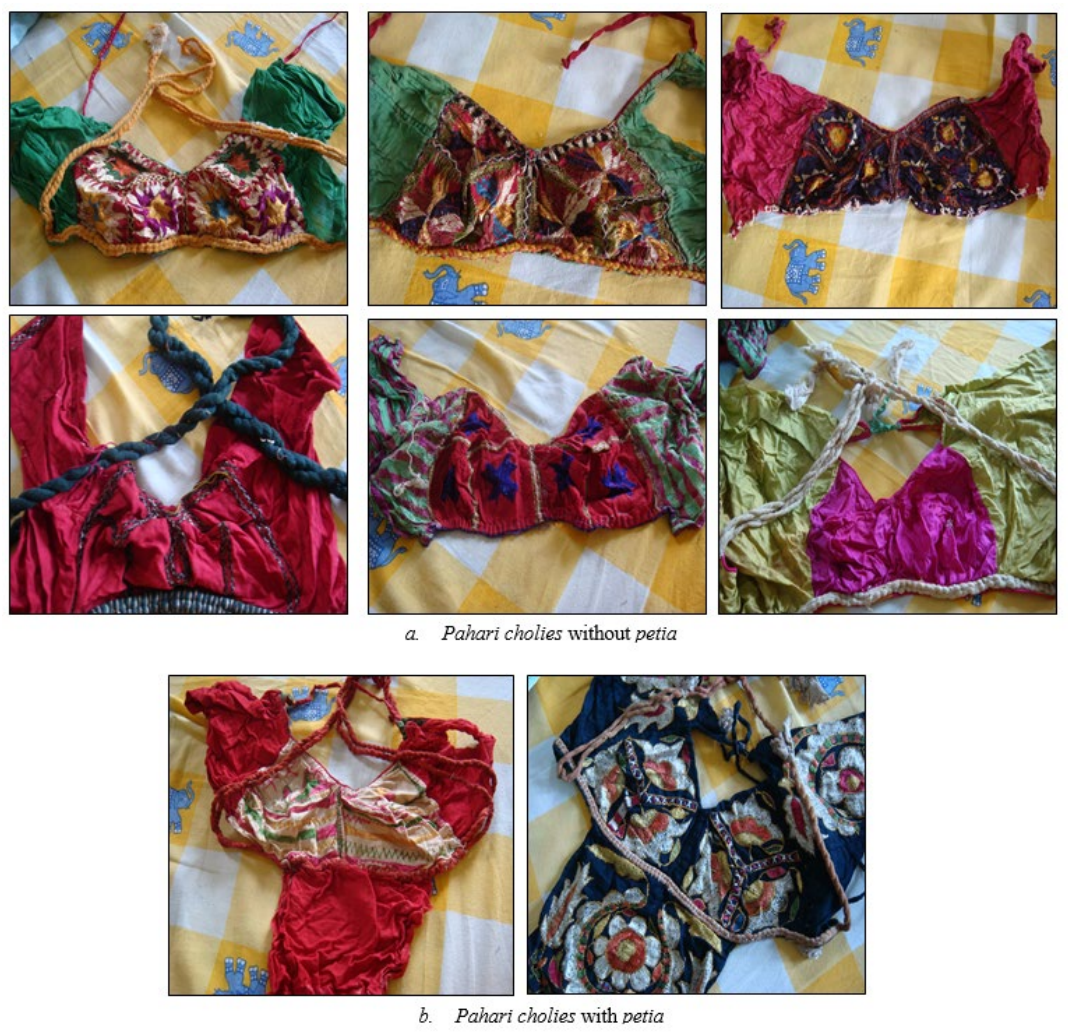

Figure 9 Pahari choli of the respondent's grandmother, Chamba; Photo: Author.

\section{CONSTRUCTION, DESIGNS AND STITCHES}

The most captivating features studied in pahari cholies are construction, designs and stitches which set them apart from cholies of another region. The spectacular masterpieces have been created using simplest of raw materials and stitches. The designs and motifs used are very specific and characterized by the selective treatment given to them. Further to analyse them in detail three pahari cholies are studied from reserved collection of National Museum, New Delhi (Accession no. 60.842/12, 64.197, 60.842/7) and others from Philadelphia Museum of Art (PMA https://www.philamuseum.org/). They gave in depth insight to their construction, designs and stitches used in embroidery.

\subsection{CONSTRUCTION}

On the basis of construction two different categories of cholies are seen. They are as follows:

\subsubsection{CHOLIES WITH PETIA WITH VERTICAL DART OR SEAM IN BREAST PIECES}

The construction of choli is worthy to note as various pieces are joined together and embroidered innovatively. In front part it has triangular shaped breast fabric pieces forming deep ' $\mathrm{V}$ ' neckline, short sleeves with gusset and rectangular waist flap called petia. 
In front each triangular shaped breast pieces have vertical seam in the center which passes from pivot point at breast as princess line (Figure 10 and Figure 11). They are joined first and then embroidered. In few samples however, only shoulder dart ending just above the pivot point is seen (Figure 12). Below the breast, rectangular shaped flap is attached over which cord is attached which is fastened at back. At back the sleeves extend which are supported by narrow widths of fabric usually 2.5 inches or less. The cords are attached for tying at neck and waist. The traditional sleeve pattern has a straight (i.e., non-shaped) armhole. The gusset (chaubugla) between sleeve and upper front allows the wearer comfort, ease of movement and lift of the arm. The most enticing part of choli is the tying cord at waist, demarcating upper portion and lower waist flap (Figure 12). It is made from two loosely twisted cotton threads attached with bodice using couching stitch or fly stitch. In couching stitch, the straight stitch is laid over the cord which is held in place by putting small stitch is the center. At back two diagonal lines are seen. In fly stitch ' $V$ ' shaped stitches are seen with small vertical stitch holding it in place over cord. In this stitch single row of diagonal stitches is seen. The neck tying cord is made of fabric. The cords are finished with fabric tassels in ends formed by giving slashes to triangular fold of fabric

The stitching is done with hand and seam allowances are finished. Plain seam is made using running stitches where seam allowances are rolled over one another which are then hemmed. This gave raised appearance to the seams. Coarser cotton thread is used for construction. The hems are folded and hemmed or tacked or many times finished using contrasting coloured piping's or facings.

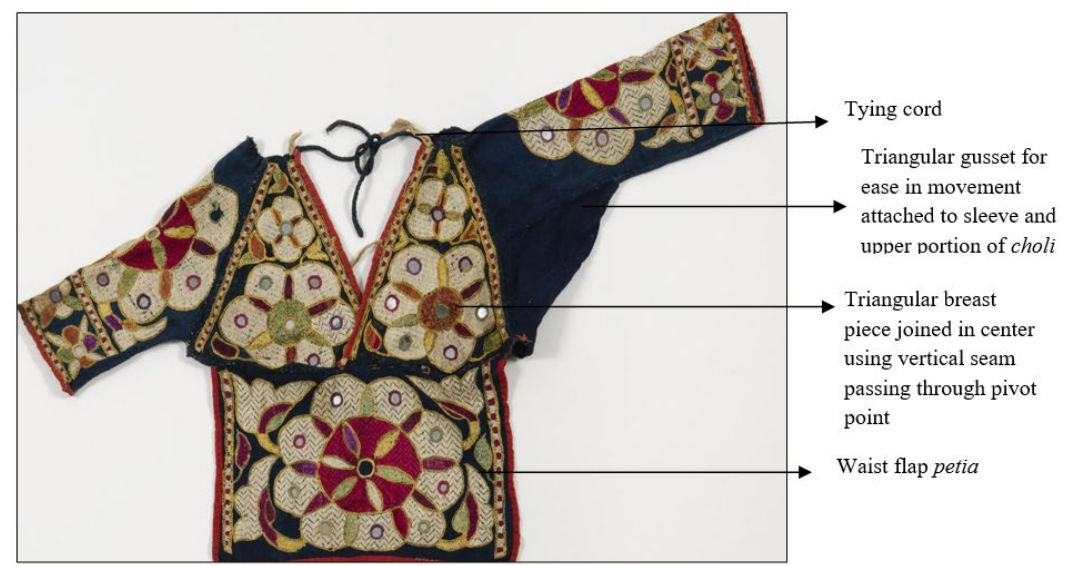

Figure 10 Components of pahari choli with petia (Front), Chamba. Source 


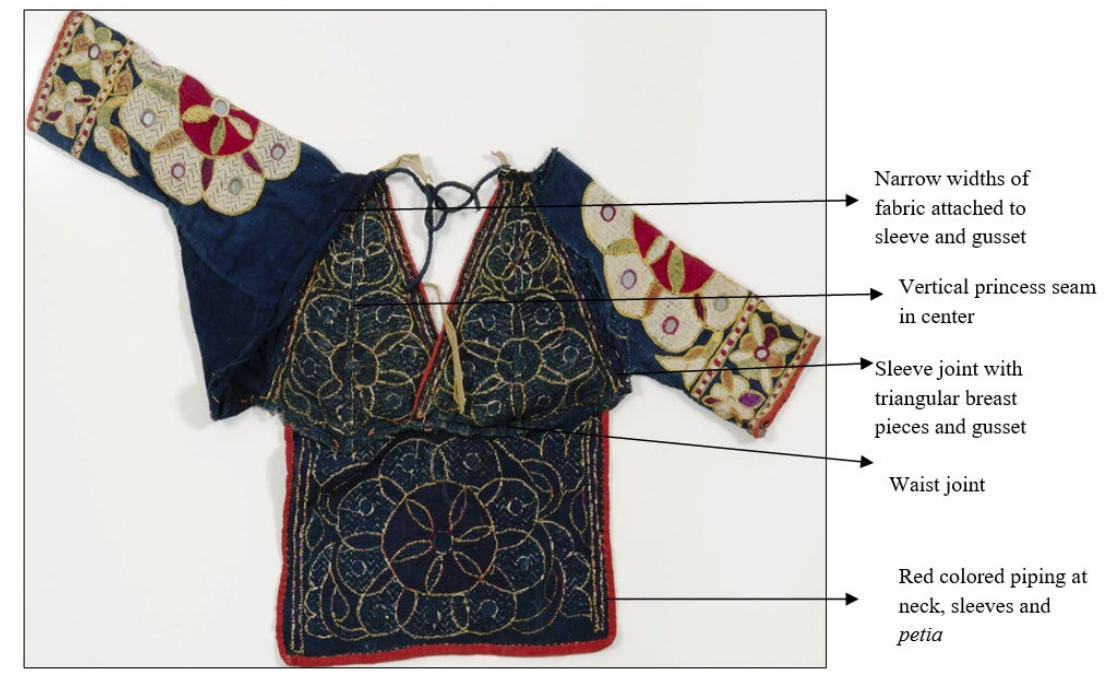

Figure 11 Components of pahari choli with petia (Back), Chamba.

Source
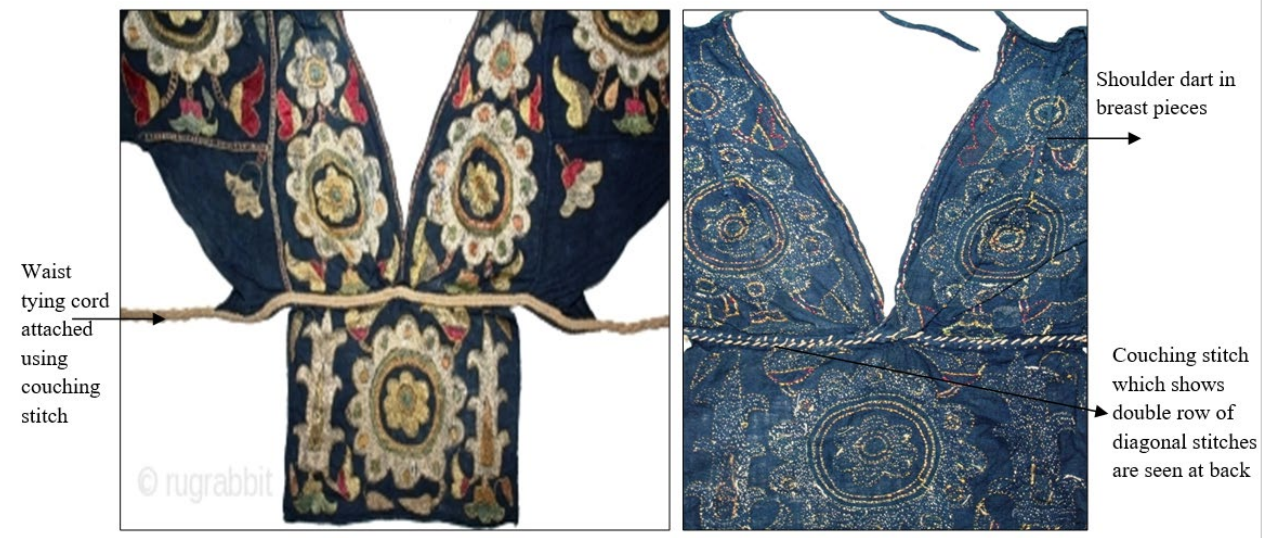

Figure 12 Back of pahari choli showing shoulder dart in breast pieces.

Source:

\subsubsection{CHOLIES WITHOUT PETIA WITH HORIZONTAL SEAM IN BREAST PIECES}

Another variation is also seen where there is no petia attached at the waist, it is small length choli covering breast area having broad ' $V$ ' neckline. These cholies are comparatively simpler and less elaborate. In this each triangular shaped breast fabric has horizontal seam passing through breast point (Figure 13). The sleeve and gusset are joined in same manner as discussed above. At back no extra width fabric is joined but at shoulder where sleeve starts small triangular fold of fabric is attached which holds the cord for tying at neck (Figure 14). The waist cord is attached in same manner in couching stitch just below breast level. 


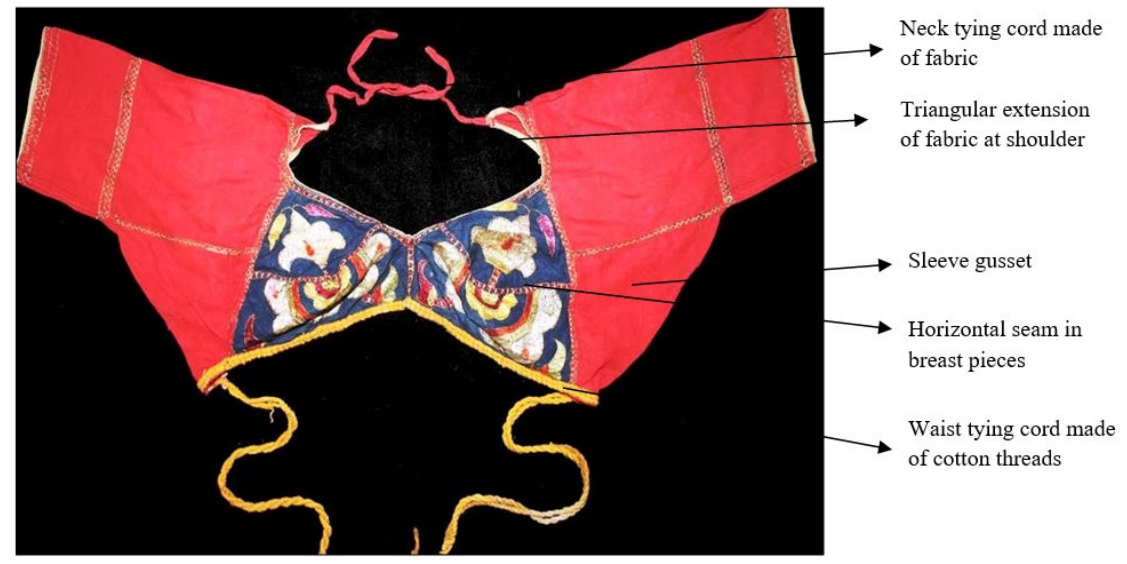

Figure 13 Components of pahari choli without petia (Front), Chamba.

Source

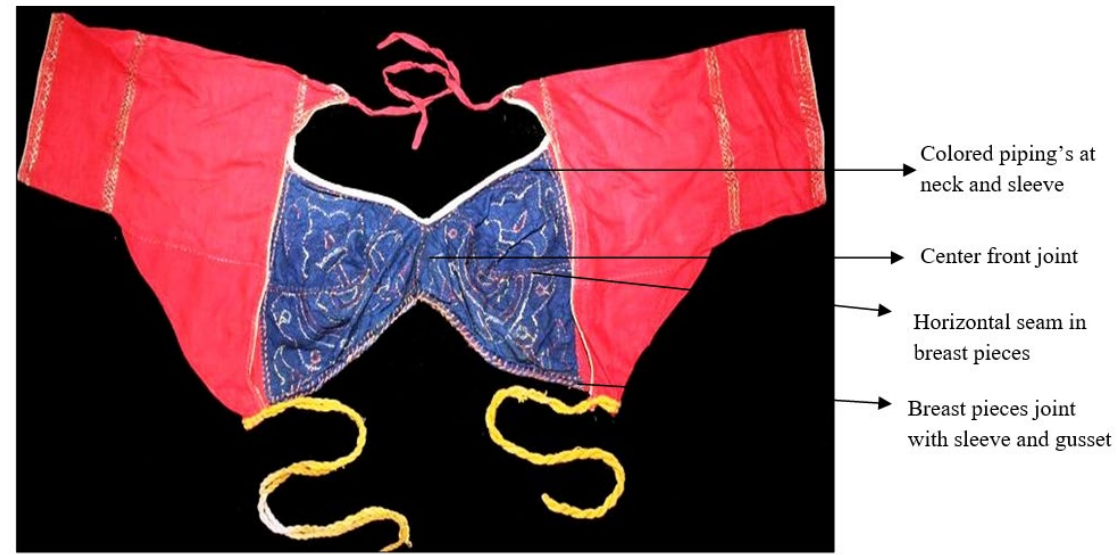

Figure 14 Components of pahari choli without petia (Back), Chamba.

Source

\subsection{DESIGNS AND MOTIFS IN PAHARI CHOLIES}

In pahari cholies two different styles are discerned on basis of designs and motifs i.e., free hand curved designs and geometrical patterns. Conspicuously, similar styles are observed in other articles as well including floral coverlets, headdress, or waist band, chaupar, patchwork embroidered pieces etc. The free hand curved designs and some geometrical patterns seen on pahari cholies are documented by getting them redrawn from miniature artist Shri Prixit Sharma, Chamba. The designs pictures are collected from various museums, literary sources, and online collections. The images are scanned, and their prints are given to miniature artist for redrawing. The hand drawn designs are documented in form of design catalogue (Plate 1). Stylistic bold motifs depicting various flora and fauna like elaborate pan buta, saru ka ped (cypress tree), elephants, peacocks and doves are seen. Floral motifs are usually rounded with concentric circles, which are further decorated with some foliage's or narrow borders to cover the leftover space. It is seen that different designs are executed in different ways in terms of placement of design, materials, and stitches. They are discussed in detail below: 

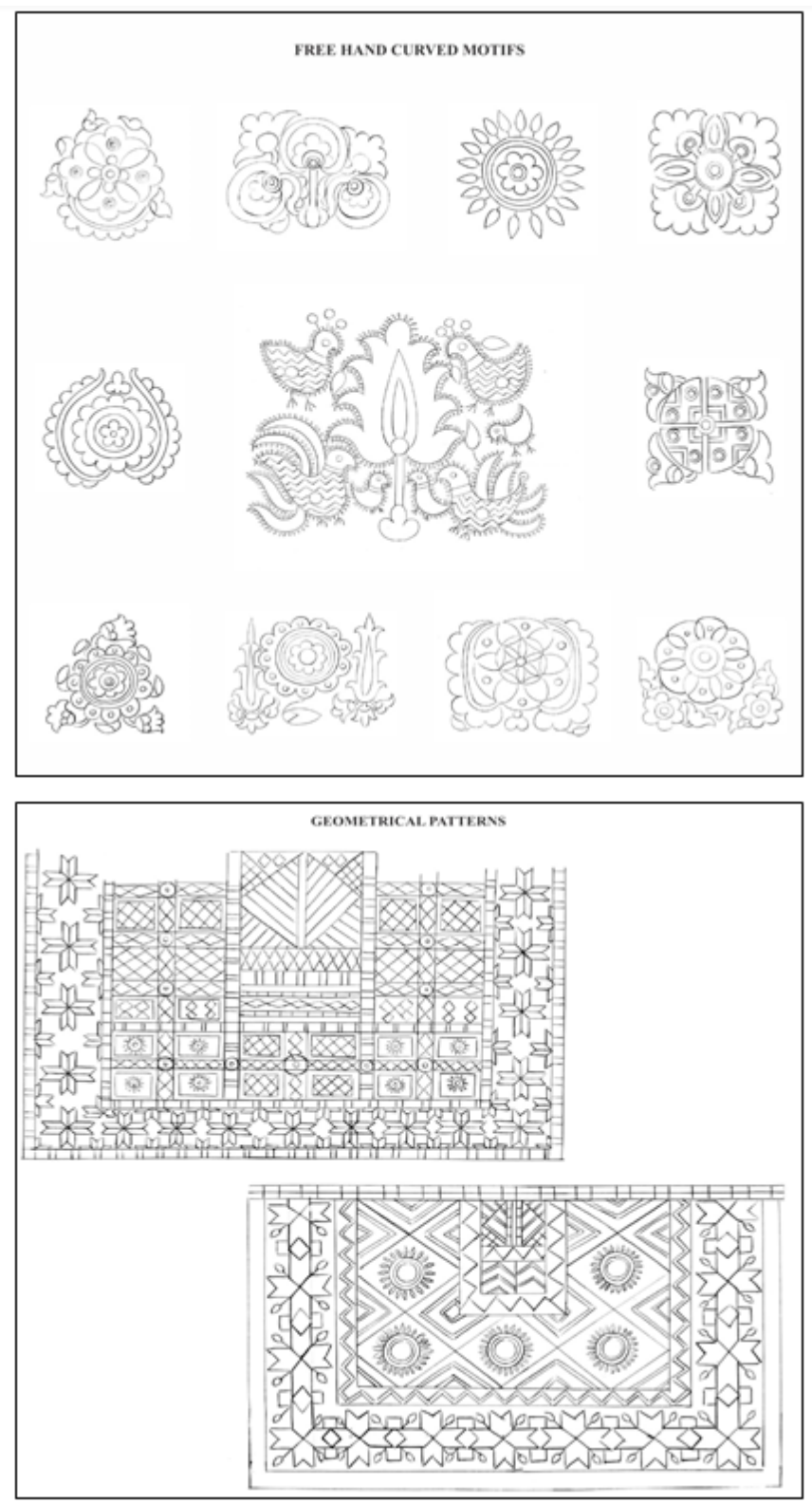

Plate 1 Design catalogue showing free hand curved motifs and geometrical motifs.

\subsubsection{PLACEMENT OF DESIGN}

The embroidery is seen on triangular shaped breast fabrics, petia and sleeves. The size of main motifs seen on petia is comparatively bigger and same motifs are adapted beautifully in other parts in choli depending on the space available. For example, the motifs on petia are the main motif in rectangular space which is beautifully adapted in triangular form in breast area. The same motif is shown on the sleeves in broad rectangular shape to cover the empty space. The free hand curved designs are firstly drawn and then embroidered. Geometrical patterns are worked directly by counting threads as in phulkari. The space is divided in small portions which are filled in variety of patterns and directions of darning and pattern darning stitches. 


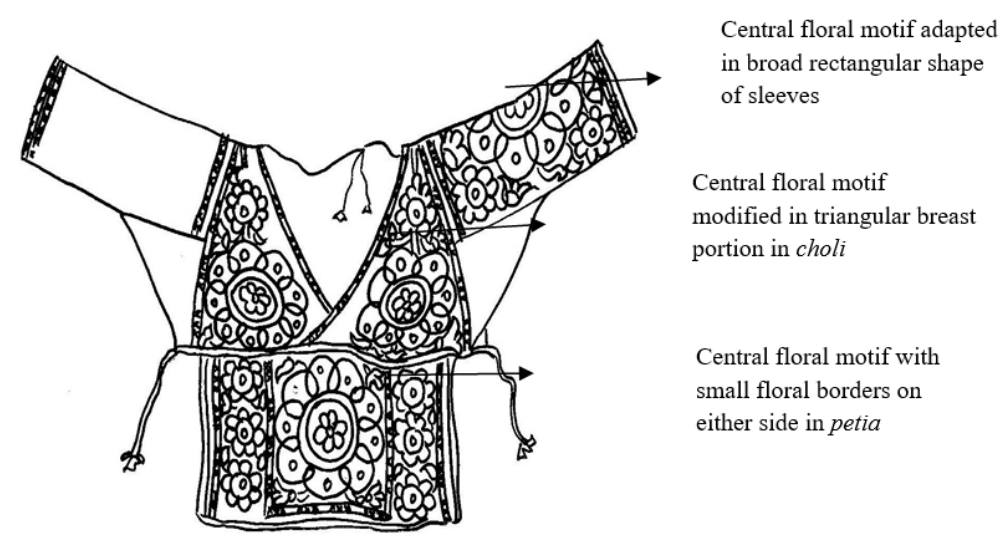

Figure 15 Layout of design in choli; Photo: Author.

\subsubsection{CHOLIES WITH FREE HAND DESIGNS}

These cholies can be with petia or without petia. The free hand curved designs are beautifully adapted in various components of these cholies. They have some distinctive characteristics which are discussed below:

- Materials: They are made on khaddar fabrics in madder red, dark indigo, buff, and brown colour. For embroidery untwisted silk yarns are used predominantly in off white, red, orange, light, and dark shades of yellow and green. Major portions of design are worked in off white; colors like yellow, green, red, and blue are marginally used to balance dark background. This colour scheme lends distinctive appearance to pahari cholies.

- Stitches: Mostly these cholies are worked in single sided stitches. The stitches most frequently used are darning stitch (straight, brick and zigzag arrangement), stem stitch, square chain stitch, double cross stitch, and herring bone stitch. The most distinctive characteristic features apart from stitches that add charm to the entire composition is the outline stitch i.e., square chain stitch in yellow color, finishing stitches and edgings.

1) Filling stitch: The embroidery is worked in single sided stitches mainly using darning stitch. These stitches are either laid in straight, brick arrangement or zigzag lines. In straight filling of darning stitches, no fixed arrangement is followed. The long and short darning stitches are laid in brick arrangement and straight rows are formed but they are not continuous (Figure 16). The same length darning stitches are taken in zig zag rows which lends very distinctive appearance (Figure 17). Many times, same motif is filled in with these variations of darning stitches (Figure 18). Small nips of fabric are taken as a result very small vertical stitches are visible on back side of fabric (Figure 19).

2) Outline stitch: The outline of motifs is worked in basic chain stitch, square chain stitch or stem stitch. The outline is chiefly seen in yellow color in square chain stitch which is characteristic feature of pahari cholies (Figure 17). Besides, basic chain and stem stitch are also seen as outline stitch (Figure 18). Outline is used to define the outlines of motifs, highlighting some intrinsic parts within motifs, and forming 
stems. Occasionally, after outline the motifs are surrounded in laisy daisy stitches in white color.

3) Finishing stitches: These are essential narrow borders enclosing embroidery close to edges or separating areas within design as narrow borders. They are worked in single and double cross stitch or herringbone stitch in set of three stitches of red and white colour alternately (Figure 16 and Figure 17).

4) Edgings: the hems are finished using contrasting colour piping's or facings (Figure 10 and Figure 11).

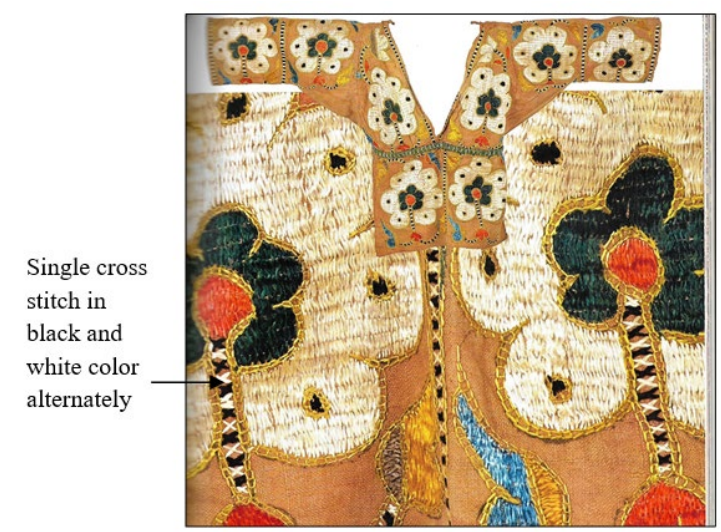

Figure 16 Brick arrangement of darning stitches; Photo: After Dhamija 2016.

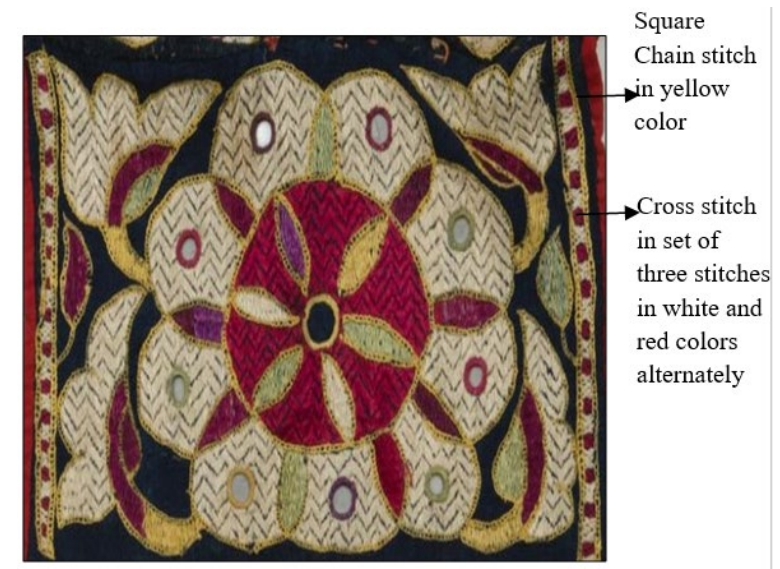

Figure 17 Zig zag line arrangement of darning stitches.

Source 


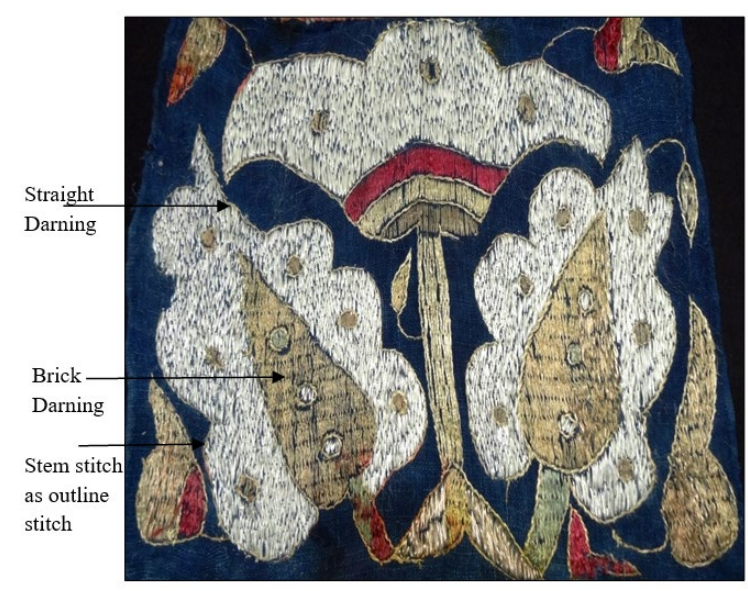

Figure 18 Straight and brick arrangement of darning stitches.

Source

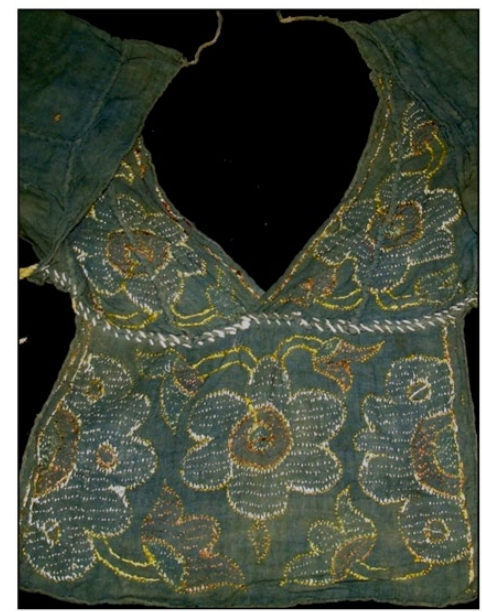

Figure 19 Vertical stitches seen at back of the fabric.

Source

\subsubsection{CHOLIES WITH GEOMETRICAL PATTERNS}

These designs are seen on cholies with petia as well as cholies without petia. Cholies with petia show elaborate designs where triangular breast pieces show free hand curved designs while sleeves and petia illustrates geometrical patterns or vice versa. Other adaptation is relatively simpler in design and stitches. The geometrical designs are worked in different manner which is discussed below:

- Materials: These cholies pertinently apply the concept of minimum utility, zero wastage in construction and sustainability. Many such examples have been studied which are created using small fragments in different colors for front breast pieces, sleeves and petia. Coarse khaddar and fine khaddar known as halwan both have been used for embroidery. The coarse weave of the khaddar helps in smooth counting of threads while embroidering unique designs seen on these cholies. For embroidery other than off white many other colors have been used for embroidery such as red, yellow, green, blue, violet etc. 

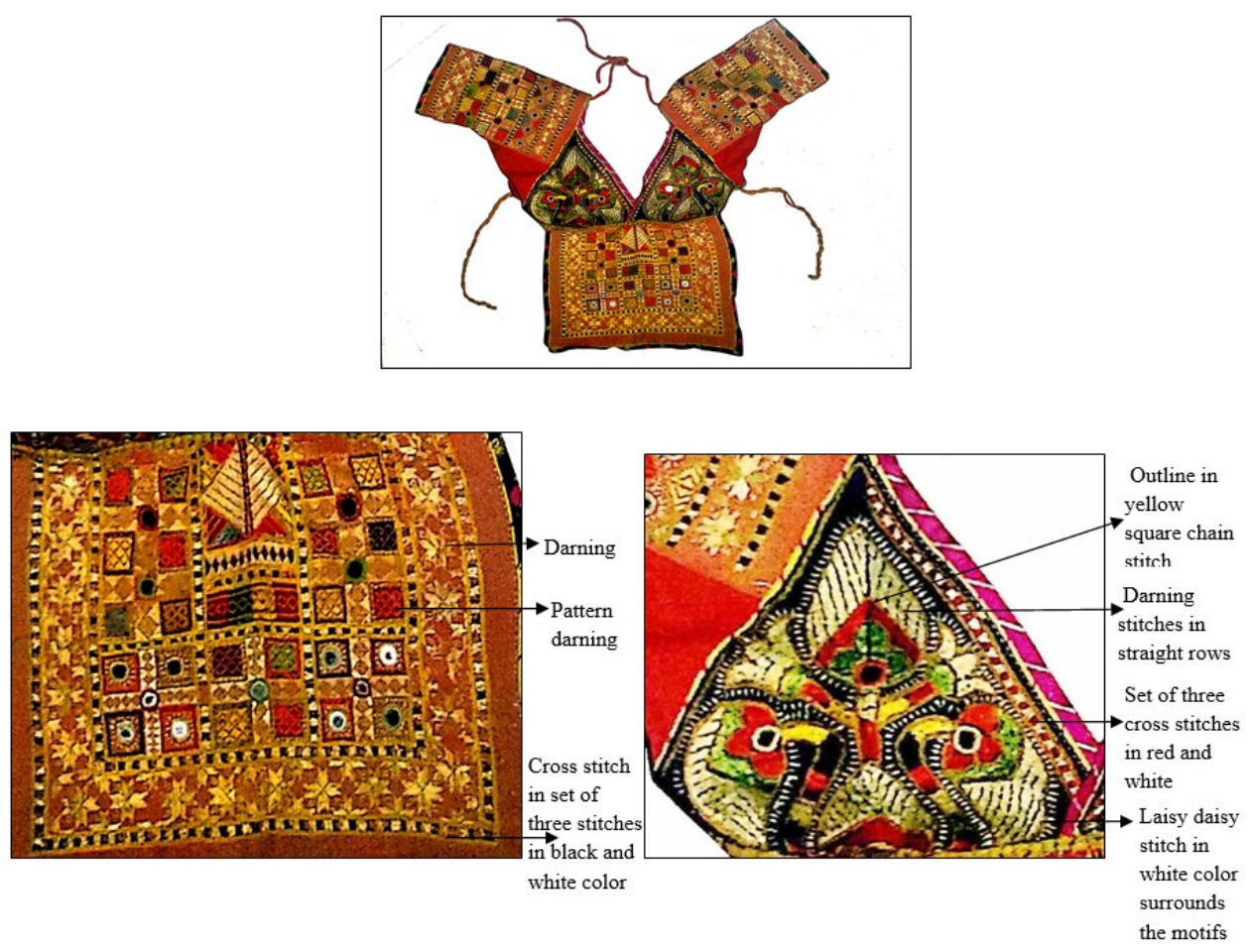

Figure 20 Choli in geometrical design and free hand curved design; After Aryan, 2010.

- Stitches: The designs in embroidery are worked by counting threads and bear marked affinities with phulkari of Punjab. Cholies with petia, usually illustrates wide variety of textures created using creative use of darning and pattern darning stitches. The darning stitches are even laid in interesting arrangement which either created straight rows or zig zag rows as seen in free hand curved motifs worked in the breast pieces. In petia, the field is divided in small squares where some of the squares show minute patterns worked using pattern darning stitches interspersed with mirrors. The mirrors are attached in buttonhole stitch which is surrounded by white laisy daisy stitch. Floral repeats worked in darning stitches are used as border enclosing the square field design. No outline is seen in these designs. In petia and sleeves, the separations in embroidery are made using narrow border in black and white cross stitch. In breast pieces the embroidery is enclosed by narrow border in red and white cross stitch. Many times, narrow border of herring bone stitch in double colors are also used to enclose embroidery. They are finished using colored piping around neck, sleeves and petia.

Cholies without petia are found to be simpler in terms of design and stitches. The breast pieces are divided in three parts where geometrical floral motifs are placed in each section which are worked in darning stitches as vertical stitches are observed at back side of the fabric. The waist cord is attached with fabric using fly stitch so diagonal stitches are seen at back side of the fabric. The embroidery is enclosed with narrow borders in two color cross stitch alternately. The designs are not outlined and edges at neck, sleeves and back are finished using piping. 

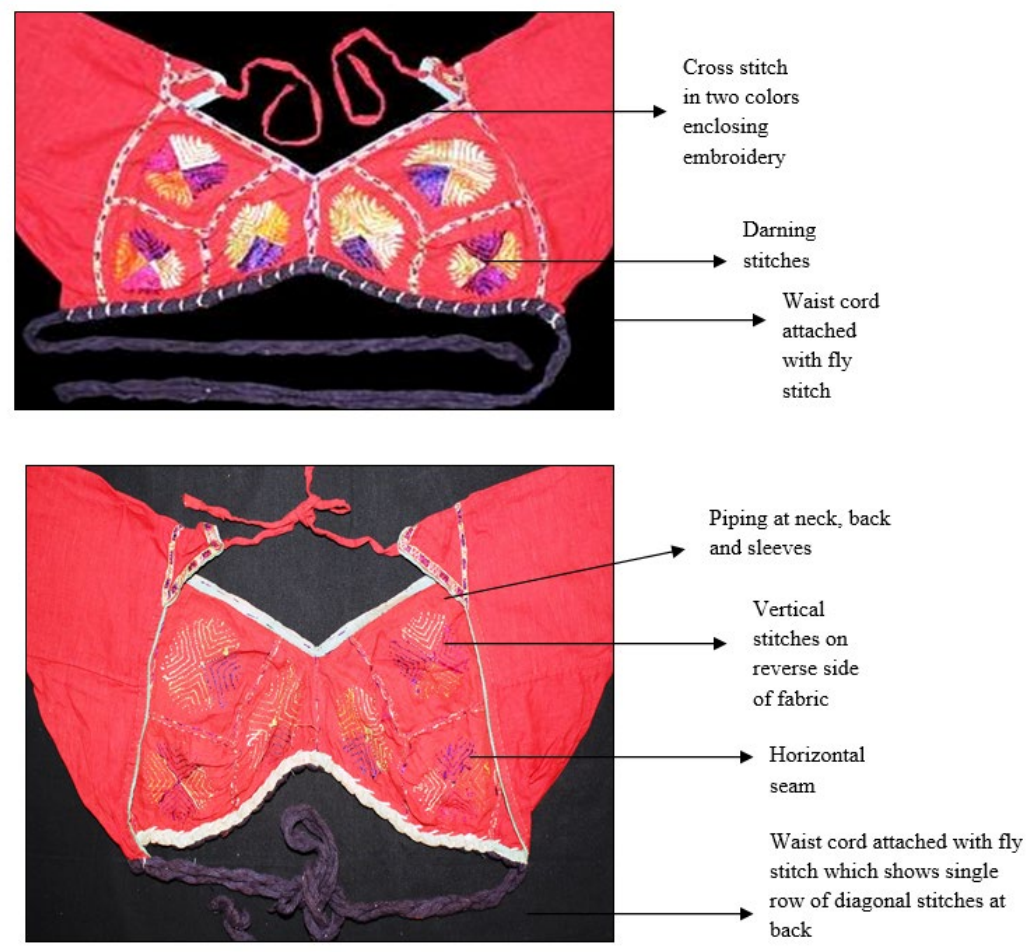

Figure 21 Choli in geometrical design.

Source

\section{CONCLUSION}

From the above discussion it can be concluded that apart from mughal influenced courtly costumes, indigenous adaptations of these costumes seem to be more prevalent with common folk. The sleeveless peshwaj with fill sleeve blouses and pahari cholies with ghagra and dupatta are befitting examples. The expansive variations of the pahari cholies are discussed below:

\section{CONSTRUCTION}

\section{1) CHOLIES WITH PETIA}

- Breast pieces: horizontal seam

- Sleeve and gusset

- Back: narrow widths of fabric are attached with sleeve; neck cord attached is attached with this strip

- Waist cord: attached using couching stitch or fly stitch

\section{2) CHOLIES WITHOUT PETIA}

- Breast pieces: Vertical seam or dart

- Sleeve and gusset

- Back: Triangular fold for shoulder extension at neck, neck cord attached 
- Waist cord: attached using couching

\section{3) FREE HAND CURVED DESIGNS}

Base fabric: Dark coloured background

Embroidery threads: Major portions of design were worked in off white and colours like yellow, green, red, and blue are marginally used to balance dark background

Stitches: Darning in straight, brick and zig zag arrangement

Outline: Square chain stitch, stem stitch

Finishing stitch: Double colour cross stitch or herring bone stitch, laisy daisy stitch surrounds the motifs in white colour

Edgings: Piping or facings

\section{4) GEOMETRICAL PATTERNS}

Base fabric: Dark coloured background with patches of fabric in different colors for sleeves, breast pieces and petia

Embroidery threads: other than off white colors like yellow, green, red, violet, and blue etc. are used.

Patterns and textures are created using

Stitches: darning, pattern darning; buttonhole stitch for attaching mirrors

Outline: no outline

Finishing stitch: double colour cross stitch or herring bone stitch

Edgings: piping or facings

\section{Directory of stitches used in construction and stitches}

\section{1) Stitch used in attaching waist cord}

Fly stitch or couching stitch both are used to hold waist cord yarns with bodice. In fly stitch at back diagonal and straight stitches are seen. In couching stitch diagonal stitches are seen at back.

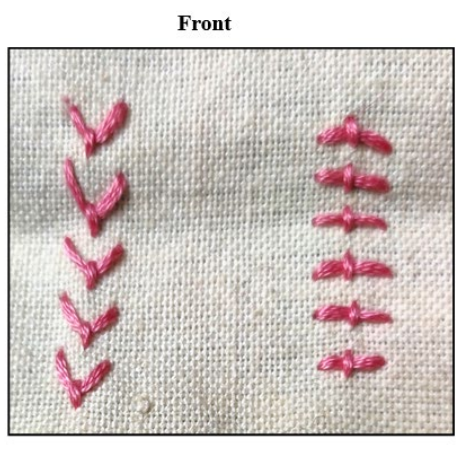

a. Fly stitch

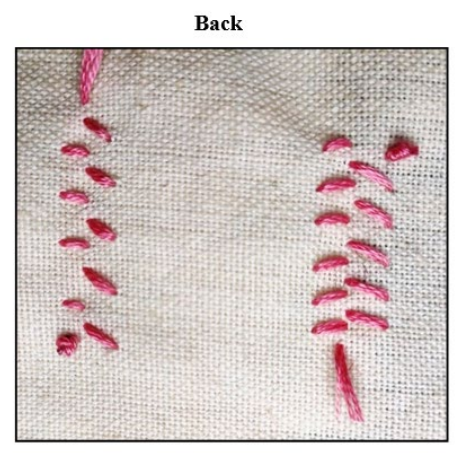

a. Fly stitch

b. Couching stitch 


\section{2) Filling stitches}

Darning stitches: They can be worked either in clear rows, brick arrangement, zig zag rows or no arrangement.

In clear rows, same length darning stitches are laid at same position following the preceding ones.

In brick arrangement, stitches of each row are evenly stitched so that they lie just below short spaces of row directly above.

In third category no arrangement of stitches is followed long and short stitches are used to fill area.

Zig zag darning stitches are filled in equal length stitches in zigzag row pattern. These stitches are used in free hand curved designs.

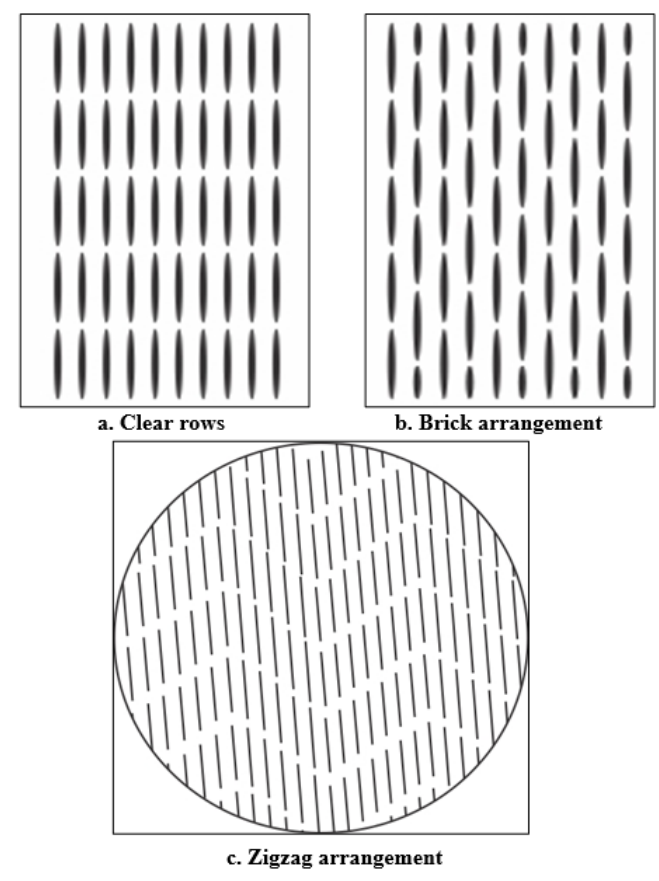

Pattern darning: Along with darning stitches pattern darning is seen in geometrical designs. They are worked in small squares where small lozenges are embroidered.
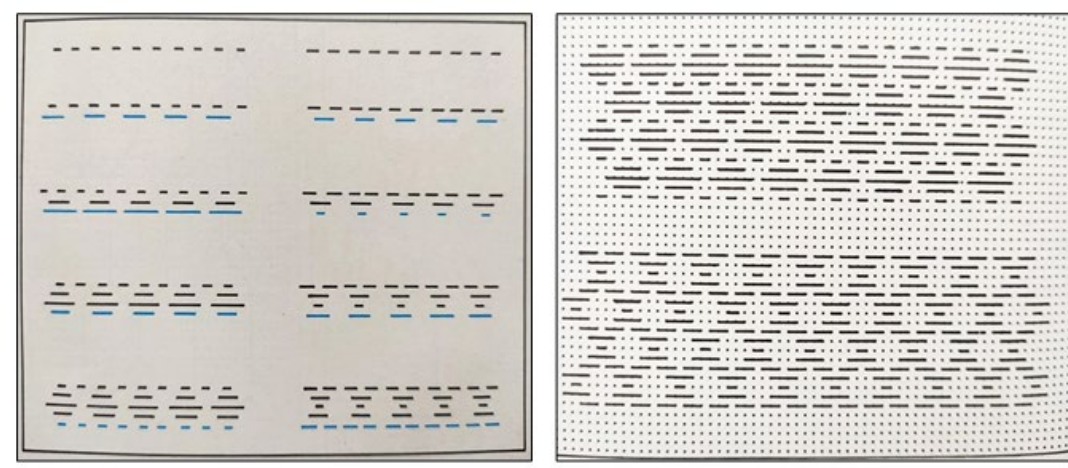

Five steps showing arrangement of stitches for two different patterns

Buttonhole stitch is used to attach mirrors. 


\section{3) Outline stitches}

Square chain stitch provides broad outline which is distinctive feature of pahari cholies. It is used all over in design and highlights the intrinsic parts within design. It is worked in yellow colour and most frequently seen in free hand curved designs. Basic chain and stem stitch are also used. Outline is not seen in geometrical patterns.

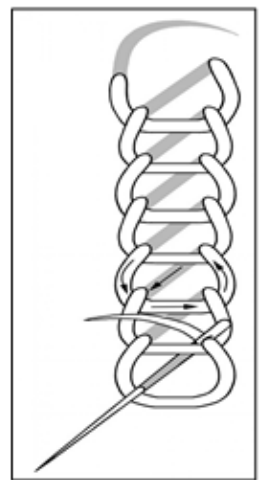

a. square chain stitch

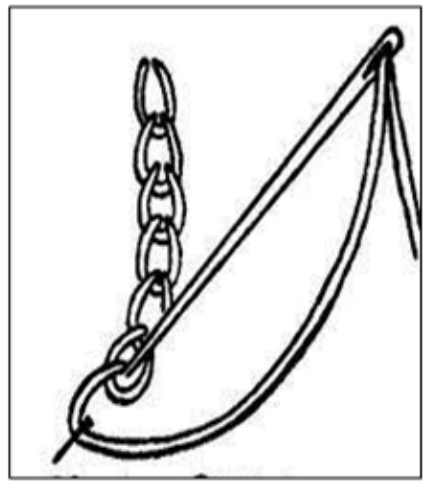

b. Chain stitch

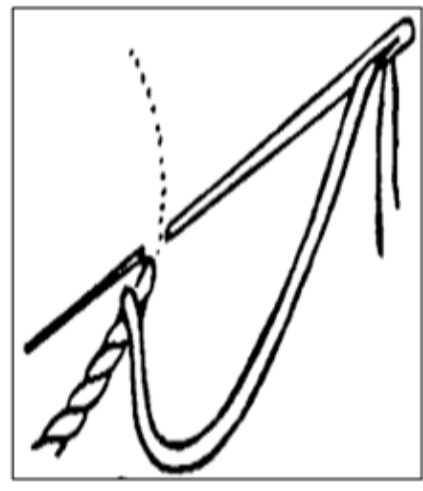

c. Stem stitch

\section{4) Finishing stitches}

Cross stitch: Double colour long armed cross stitch in red or black and white is characteristic features widely used in pahari cholies. Single or double colour basic cross stitch is also seen

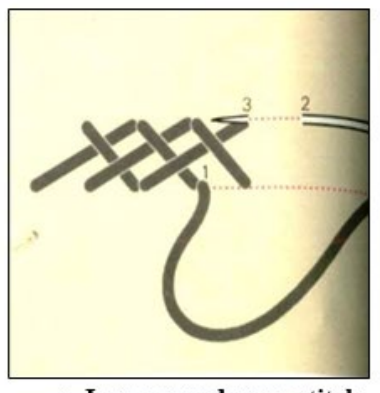

a. Long armed cross stitch

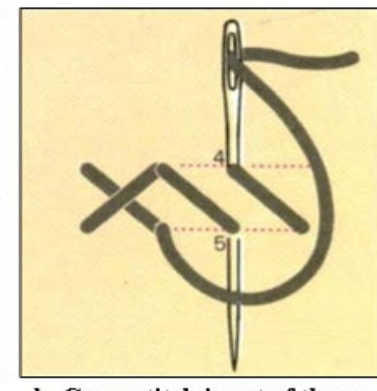

b. Cross stitch in set of three

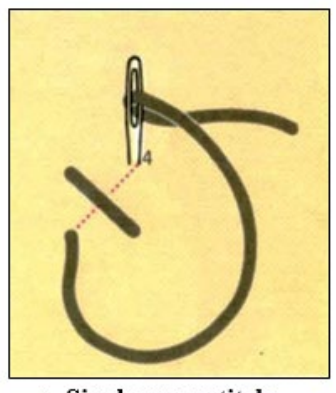

c. Single cross stitch

Herringbone stitch: Double herringbone stitch is two rows of herringbone that interlace. Rows worked in black and white colors.

These borders are outlined either in square chain stitch, running stitch or stem stitch.

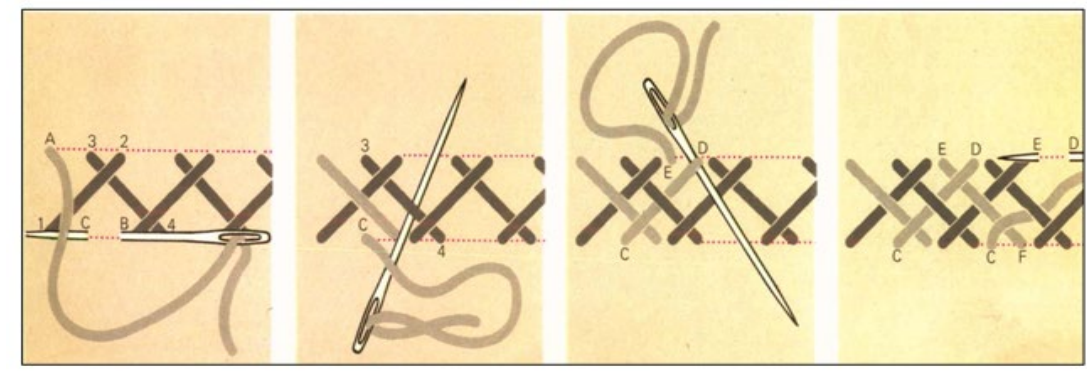

Steps showing formation of double herringbone in two colors 
Laisy daisy stitches: single chain stitches are used to surround free hand curved designs in white colour.

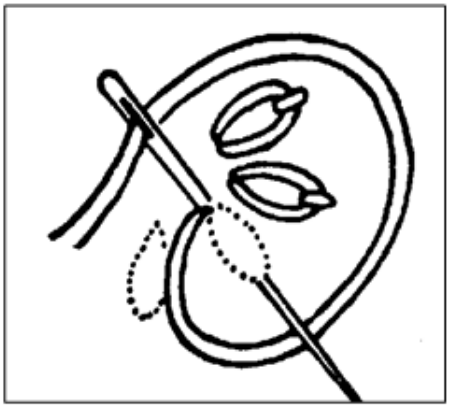

Laisy daisy stitch

5) Edgings

Contrasting colour piping and facing are used to finish hems at front neckline, back, sleeve and petia.

Fabric tassels are attached at ends of neck cord and waist cord. A square is folded in triangular shape and slashes are given in ends.

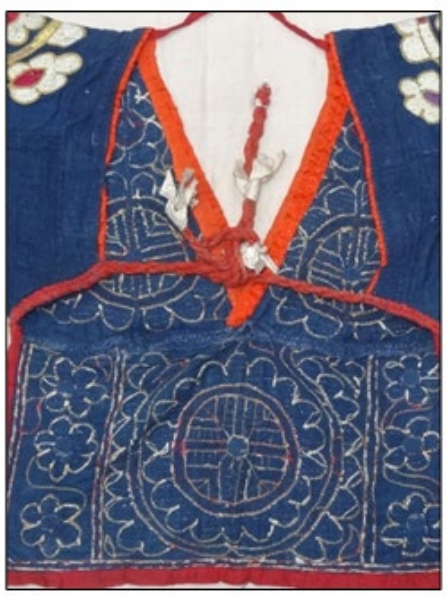

\section{REFERENCES}

Nabiyya, A. N. (1997). India Ru Al Dribirunie Hindus Ki Lahkan Vidyayo, Their Mathematics and Related Subjects, National Book Trust, India.

Dhamija J., (2016), Woven treasures : Textiles from the Jasleen Dhamija Collection', Saffornart Mumbai, 52, 53.

Goswamy, B.N., (1993) Indian Costumes- in collection of the calico Museum of Textiles, volume V, Historic Textiles of India at Calico Museum, Ahmedabad, 1993, published by D.S. Mehta on behalf of Calico Museum of Textiles, Sarabhai Foundation, Ahemdabad, 380004, India.

Pathak A., (2017), Ramayana : poetic expressions on temple hanging, Technical Study, National Museum New Delhi, 68.

Sachdeva A. and Sharma, S., editors Dr. B.R. Mani, Dr. Anamika Pathak, (2019). Identity amidst a crowd : Textiles and costumes of the anthropology department, Textiles : Binding threads between cultures from National Museum Collections', published by National Museum, Janpath, New Delhi. 
Subhashini Aryan, (2010) Folk Embroidery of Western Himalaya. (New Delhi : Rekha Prakashan, 2010), 34-35.

Textile Gallery (2020). Museum Of Kangra Art, Dharamshala.

Woman's Blouse (2000). Philadelphia Museum of Art.

chamba choli. (N.d.). https://www.etsy.com/sg-en/search?q=chamba\%20choli sushmit (2016). Pahari Embroidery: The Bold Cholis Of Himachal Pradesh. 